\title{
Evaluation of the risk of a stripping perforation with gates-glidden drills: serial versus crown-down sequences
}

\author{
Tauby Coutinho-Filho(a) \\ Gustavo De-Deus ${ }^{(a)}$ \\ Eduardo Diogo Gurgel-Filho(b) \\ Ana Carolina Rocha-Lima(c) \\ Katia Regina Cervantes Dias ${ }^{(\mathrm{d})}$ \\ Carlos Augusto Barbosa(a)
}

(a) PhDs, Department of Endodontics; (d) PhD, Department of Restorative Dentistry - State University of Rio de Janeiro (UERJ), RJ, Brazil.

(b) PhD, Department of Endodontics, University of Fortaleza (UNIFOR), CE, Brazil.

(c)Master's Candidate, Department of Endodontics, Piracicaba Dental School, State University of Campinas (UNICAMP), SP, Brazil.

\section{Corresponding author}

Eduardo Diogo Gurgel-Filho

Av. Dom Luis, 1233/31 1 - Aldeota

Fortaleza - CE - Brazil

CEP: 60160-230

E-mail: gurgeleduardo@unifor.br

\begin{abstract}
The aim of this study was to evaluate the remaining dentine/ cementum thickness using Gates-Glidden burs in serial and crown-down sequences and to observe which of the two sequences is the safest for preparing mesial roots of molars. Thirty-six left and right human mandibular first molars were selected. Standard access cavities were made and initially explored with Flexofiles sizes 10 and 15 until the tip was visible at the apex. The teeth were embedded in a muffle specially developed for this study using a PVC tube with two parallel metal rods in its lid. Each tooth-block was sectioned $3 \mathrm{~mm}$ apically to the furcation using a low-speed saw with a diamond disc. The tooth-block was examined under a microscope and an initial image was captured by a digital video system with $8 \mathrm{X}$ and $12 \mathrm{X}$ magnifications. Finally, the tooth-blocks were reassembled in the muffle so that the canals could be instrumented. After instrumentation the area of each mesial canal as well as the smallest distance to the root furcation were measured again. The mesio-buccal canals (crown-down order) and the mesio-lingual canals (serial sequence) presented an average area of $0.46 \pm 0.16 \mathrm{~mm}^{2}$ and $0.88 \pm 0.27 \mathrm{~mm}^{2}(P<0.01)$, respectively. The mean values of the smallest distance to the furcation for the mesio-buccal and mesio-lingual canals were $0.66 \pm 0.19 \mathrm{~mm}$ and $0.39 \pm 0.13 \mathrm{~mm}(P<0.01)$, respectively. The remaining dentine/cementum thickness using Gates-Glidden burs was greater in the crown-down sequence than in the serial sequence.
\end{abstract}

Descriptors: Dental instruments; Endodontics; Molar. 


\section{Introduction}

The Gates-Glidden bur plays an important role among the instruments used during root canal preparation. Grossman ${ }^{1}$ (1982) dated its first utilization in 1885 . However, it was only used after studies performed during the 70's when the concepts of Cleaning \& Shaping were reintroduced in Endodontics. ${ }^{2-4}$

Its low cost and high cutting power associated with its simplicity of use made it a widely used instrument for the preparation of the straight portion of root canals. Abou-Rass et al. ${ }^{5}$ (1980) demonstrated that the mesial canals of inferior molars do not assume a central position in relation to the root. The area between the canal and the root furcation possesses thinner walls and is therefore named the 'Risk Zone'. Another aspect is related to the transportation of mesial canals in inferior molars towards the furcation. The great flaring capacity of these instruments may lead to mechanical flaws in the root canal, especially at the "Risk Zone". ${ }^{6}$

Excessive flaring of the cervical and middle thirds in flat roots may lead to a pronounced decrease of the dentinal wall thickness or even result in a strip perforation towards the furcation. ${ }^{78}$ Thin dentine walls increase root permeability and the possibility of fracture, not only during filling, but also during tooth functioning. ${ }^{9}$ Especially due to their cutting power, Gates-Glidden (GG) burs have suffered criticism regarding their employment. ${ }^{10}$ Although the use of GG burs may be regarded as the traditional preparation technique, there are few studies analyzing their effect in the "Risk Zone" of mandibular molars. ${ }^{3}$

Even after several years in evidence, their operative sequence has still not been well established in literature, remaining, in most cases, up to the operator's common sense. The serial sequence is normally the most common technique applied..$^{4,11}$

This study aimed to evaluate the remaining dentine/cementum thickness using Gates-Glidden burs in serial and crown-down sequences and to observe which of the two sequences is the safest for preparing the mesio-cervical area of molar roots.

\section{Material and Methods}

This study was revised and approved by the Ethics Committee, Nucleus of Collective Health Studies,
State University of Rio de Janeiro, Rio de Janeiro, RJ, Brazil. A sample of 36 human first mandibular left and right molars, free from cracks, with similar anatomical characteristics were selected from the tooth bank of the State University of Rio de Janeiro. Mean root canal curvature of the teeth used in this study was between $17^{\circ}$ and $25^{\circ}$. The teeth were autoclaved and kept in $0.5 \% \mathrm{NaOCl}$ for no longer than $24 \mathrm{~h}$. Standard access cavities were made and all the canal orifices were located and initially explored with ISO size 10 and 15 stainless steel Flexofiles $^{\circledR}$ (Dentsply-Maillefer, Ballaigues, Vallorbe, Switzerland) until the tip was visible at the apex. $5.25 \%$ sodium hypochlorite (B Herzog - 8366, Rio de Janeiro, RJ, Brazil) was used to irrigate the canal during all steps.

A modified version of the muffle system ${ }^{12}$ was used, in which each molar was embedded in epoxy clear resin (Arazyn 1.0 - Araquímica, Araçariguama, SP, Brazil) up to its furcation. The teeth were embedded in a muffle specially developed for this study using a PVC tube (Tigre Ltda., Rio Claro, SP, Brazil) with two parallel metal rods in its lid (Figure 1). Two equidistant nails and screws were

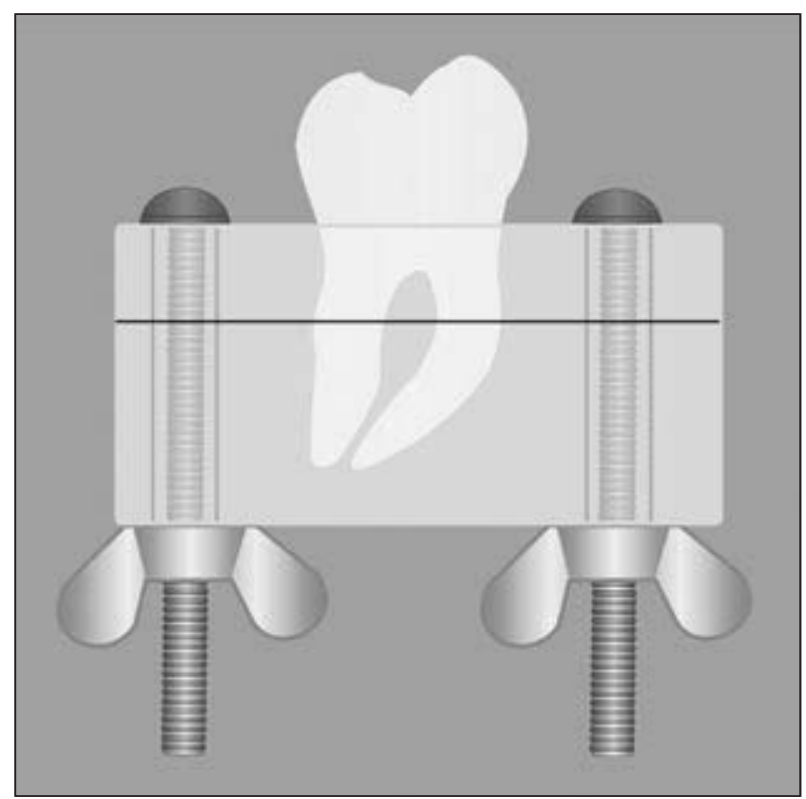

Figure 1 - Setup of the Muffle Model System (tooth-block model). The blocks were sectioned by a precision cutting apparatus using a $0.33 \mathrm{~mm}$ thick diamond disk to reduce the loss of dental tissue. 
used as metallic guides to permit a safe remounting of the teeth.

Each tooth-block was sectioned $3 \mathrm{~mm}$ apically to the furcation using a low-speed saw (Isomet, Buehler, Ltd. Lake Bluff, NY, USA) with a diamond $\operatorname{disc}(\varnothing 125 \mathrm{~mm} \times 0.35 \mathrm{~mm} \times 12.7 \mathrm{~mm}-330 \mathrm{C})$ while constantly irrigated. Each tooth-block was examined under a microscope (Axiscoppe - Carl Zeiss Vision Gmbh, Hallbergmoos, München, Germany) and an initial image was captured by a digital video system (Carl Zeiss Vision Gmbh, Hallbergmoos, München, Germany) with $8 \mathrm{X}$ and $12 \mathrm{X}$ magnifications. Finally, the tooth-blocks were reassembled in the muffle so that the canals could be prepared for instrumentation.

These initial images were submitted to computer-assisted evaluation. The KS 400 image system 3.0 (Carl Zeiss Vision Gmbh, Hallbergmoos, München, Germany) was used for image analysis and processing. The software allowed us to measure the root canal area and the smallest distance to the furcation (SDF) using a semi-automatic process of segmented pixel shades. In order to achieve this, the images were converted to 256 gray tones, as these achieved the best results in the pilot study. Each image captured by the computer was gauged, eliminating any possible distortion. A protocol (macro) was developed to analyze all images, making the process more efficient and easier to reproduce. The measurements obtained by image analysis were repeated twice to ensure reproducibility.

After capture and initial analysis of the mesial root canals, the GG drills (Dentsply-Maillefer, Ballaigues, Vallorbe, Switzerland) were used in crowndown order (GG4, GG3 and GG2) in the mesio-buccal canal (G1). To operate the drills, a conventional low-speed hand piece operating at 2,500 rpm was used. The movement performed with the rotary instruments was slight apical pressure, ups and downs with only one penetration with each drill. The depth of the drill was determined by its clinging inside the radicular canal. ${ }^{7}$ Between the use of each drill, a recapitulation with the apical file was used with additional irrigation with $1 \mathrm{ml}$ of $5.25 \% \mathrm{NaOCl}$. In the mesio-lingual canal (G2), the GG drills were used in the same way, although in serial sequence: GG2, GG3 and GG4.

After instrumentation, each tooth-block was reexamined under a microscope and new images of the mesial root canal were captured. At this moment the area of each mesial canal as well as the smallest distance to the root furcation was remeasured.

The initial and final cross-section areas, as well as the smallest distance to the root furcation, were treated and statistically analyzed. After assessment of the non-normality of the data distribution, the ANOVA analysis was employed. When differences were found, Dunn's multiplecomparison test was used to isolate the statistically significant group. The level of significance was set at $\mathrm{p}<0.05$. Origin 6.0 (Microcal Software, Inc., Northampton, MA, USA) and SPSS (Statistics 4.0 software, SPDD International BV, Gorinchem, The Netherlands) were also used as analytical tools.

\section{Results \\ Cross-section area}

The initial cross-section area values for the mesio-buccal canals (G1) varied between 0.12 and $0.77 \mathrm{~mm}^{2}$, presenting an average of $0.24 \pm 0.10 \mathrm{~mm}^{2}$, while the initial cross-section area values for the mesio-lingual canals (G2) varied from 0.11 to $0.81 \mathrm{~mm}^{2}$, revealing an average of $0.23 \pm 0.11 \mathrm{~mm}^{2}$. Because of the high values presented by the standard deviation, it was possible to confirm the existence of great variability of the anatomy of the mesial root canals. However, after statistical treatment, it was possible to determine that no statistical difference $(P>0.05)$ could be observed between the initial cross-section area of the mesio-buccal and the mesio-lingual canals since their averages were extremely similar.

After instrumentation, the final area of the mesio-lingual canals (G2) assumed values that varied between 0.37 and $1.24 \mathrm{~mm}^{2}$, indicating an average of $0.88 \pm 0.27 \mathrm{~mm}^{2}$. The mesio-buccal canals (G1) assumed values which varied between 0.37 and $1.45 \mathrm{~mm}^{2}$, presenting an average of $0.46 \pm 0.16 \mathrm{~mm}^{2}$. It was possible to determine significant differences between initial and final areas $(P<0.01)$. The com- 

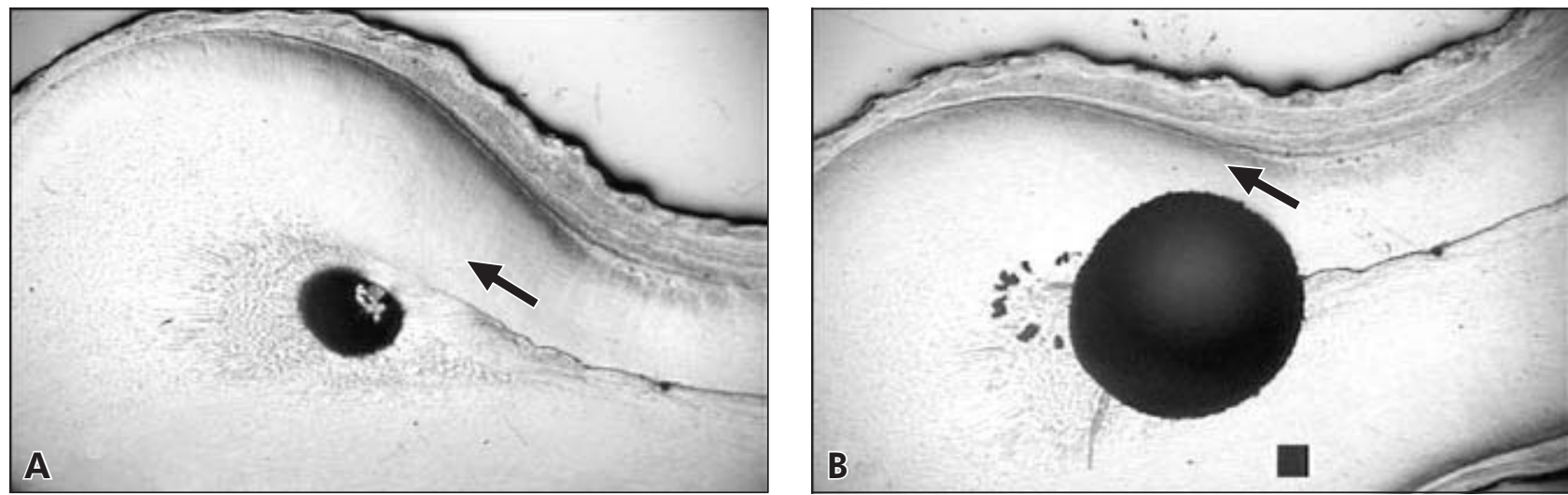

Figure 2 - (A) Initial cross-section area of the mesio-lingual canal of sample 6. (B): After Gates-Glidden preparation in serial sequence, a greater increase of the cross-section area $(249.5 \%)$ and an excessive drop in the smallest distance to the furcation (70.3\%) can be observed.
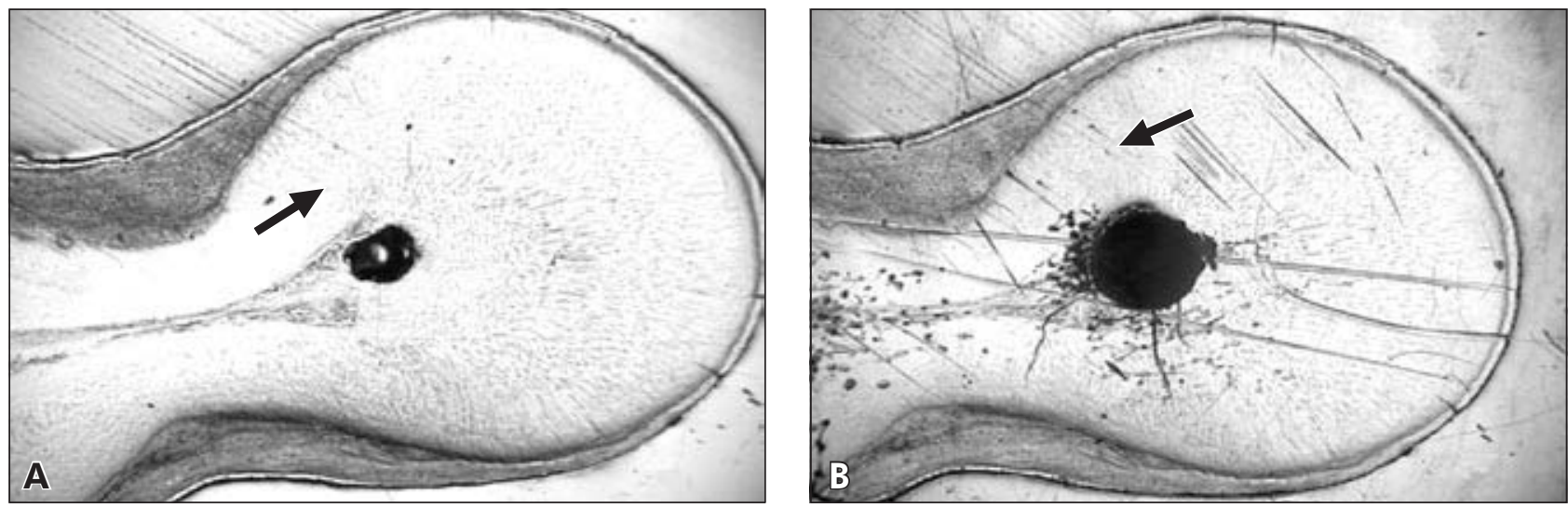

Figure 3 - (A) Initial cross-section area of the mesio-buccal canal of sample 7. (B): After Gates-Glidden preparation in crowndown sequence, a limited increase of the cross-section area (79.2\%) and a moderate reduction in the smallest distance to the furcation (17.3\%) can be observed.
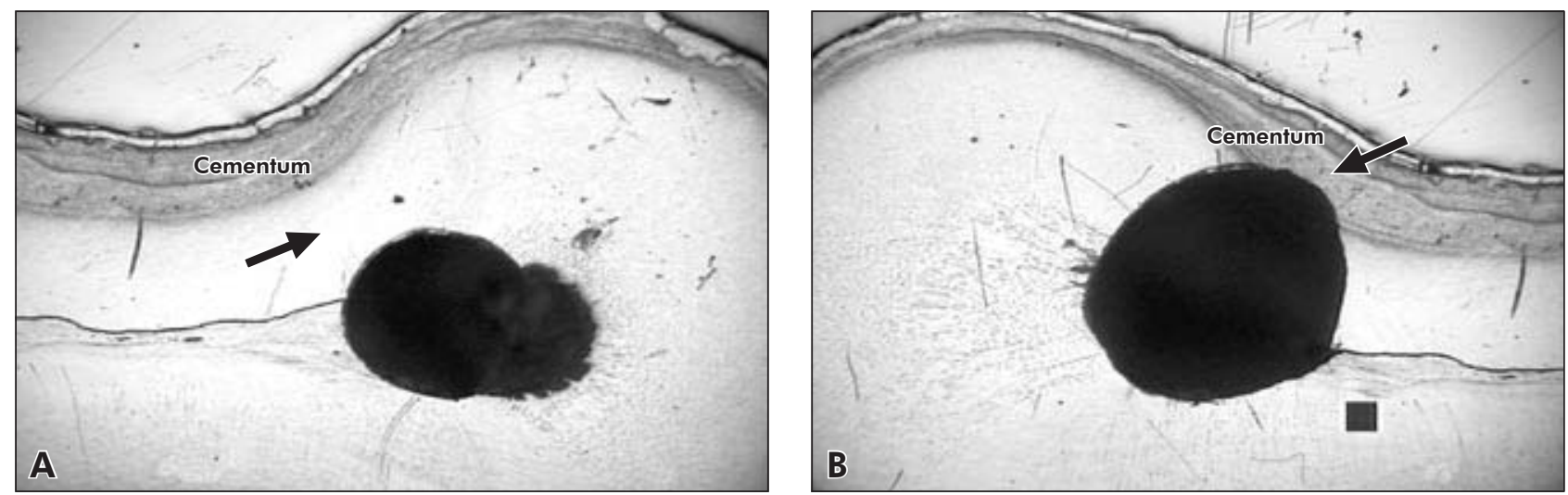

Figure 4 - (A) Cross-section area of a mesio-buccal canal after Gates-Glidden preparation in crown-down sequence. (B): Cross-section area of a mesio-lingual canal after Gates-Glidden preparation in serial sequence. A total rupture of the dentine/ cementum wall, leading to the furcation area, can be observed. 


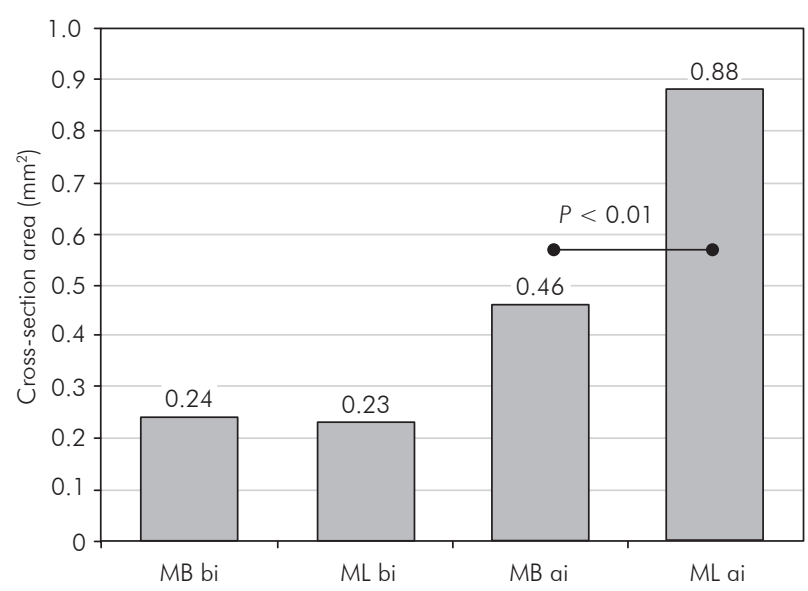

Graph 1 - Cross-section area means before (bi) and after instrumentation (ai), in the MB (mesio-buccal) and ML (mesio-lingual) canals.

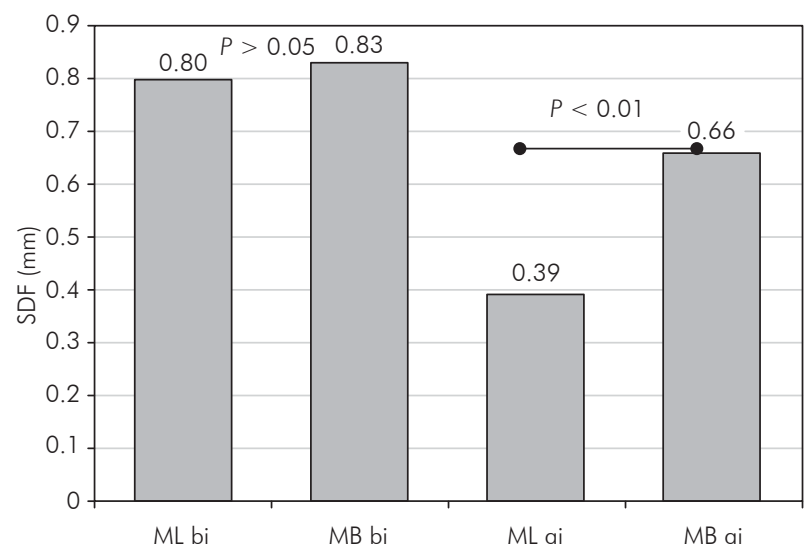

Graph 2 - Smallest distance to furcation (SDF) means before (bi) and after instrumentation (ai) in the MB (mesio-buccal) and ML (mesio-lingual) canals.

parison between groups can be visualized in Figures 2, 3 and 4 and Graph 1.

The SDF values for the mesio-lingual canals (G2) varied between 0.55 and $1.11 \mathrm{~mm}$, presenting an average of $0.80 \pm 0.15 \mathrm{~mm}$. The SDF values for the mesio-buccal canals (G1) varied between 0.53 and $1.29 \mathrm{~mm}$, and demonstrated an average of $0.83 \pm 0.17 \mathrm{~mm}$. It was possible to encounter a modest variation when comparing the SDF values found in the mesio-buccal and mesio-lingual canals before instrumentation. No significant difference between the mesio-buccal and mesio-lingual canals was found $(P>0.05)$.

After instrumentation, the SDF values for the

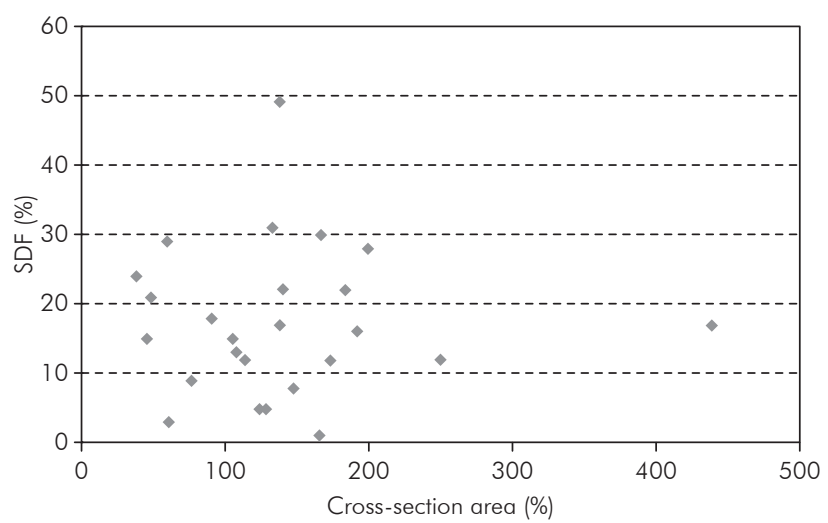

Graph 3 - Relationships between the smallest distance to furcation (SDF) and the cross-section area in the mesiobuccal (MB) canal after $G G$ preparation in crown-down sequence.

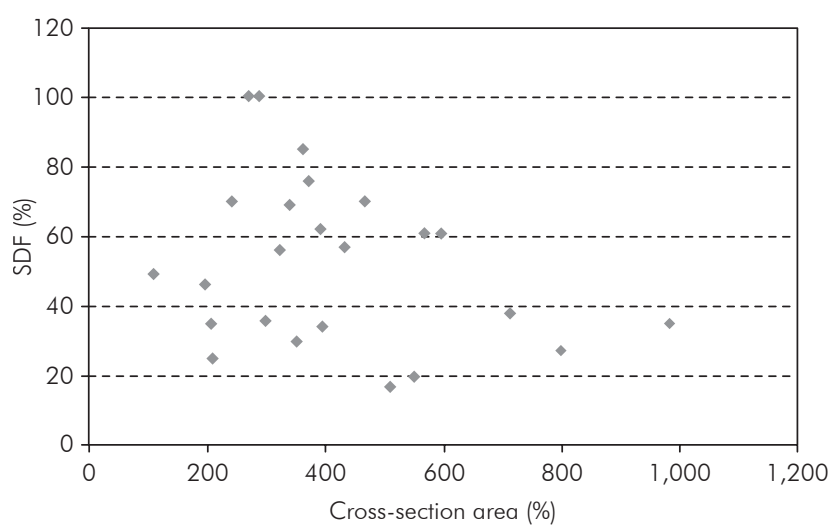

Graph 4 - Relationships between the smallest distance to furcation (SDF) and the cross-section area in the mesio-lingual (ML) canal after $G G$ preparation in serial sequence.

mesio-lingual canals (G2) varied from 0 to $0.90 \mathrm{~mm}$, presenting an average of $0.39 \pm 0.13 \mathrm{~mm}$. It was possible to determine a significant difference between the initial and final SDF values $(P<0.01)$. It is important to point out that two samples suffered stripping perforation, and therefore their SDF values were considered to be zero (Figure 4). After instrumentation, the SDF values for the mesio-buccal canals (G1) varied from 0.38 to $1.16 \mathrm{~mm}$, presenting an average of $0.66 \pm 0.19 \mathrm{~mm}$. It was possible to determine statistically significant differences between the groups $(P<0.01)$. The comparison between groups can be visualized in Graph 2. The relationship between the data of the cross-section area and 
the smallest distance to the furcation can be visualized in Graphs 3 and 4.

\section{Discussion}

The present work attempted to simplify the muffle system method. A PVC tube, easily found in the marketplace, was used to create resin-blocks, without the necessity of industrial sophistication, therefore simplifying the process. Two equidistant nails and screws were used as metallic guides to permit a safe remounting of the teeth.

The furcation area of the first inferior molars, sectioned at a point located between 2 and $3 \mathrm{~mm}$ bellow the furcation of the roots, presented a concave aspect in $100 \%$ of the mesial roots and $99 \%$ of the distal roots. ${ }^{13}$ Several authors have described an area 3 to $4 \mathrm{~mm}$ below the entrance of the canals to be the most sensitive location for the perforation of mesial molar roots after the use of rotary instruments. ${ }^{5,14,15}$ Based on these results, the present study opted to section the root samples $3 \mathrm{~mm}$ bellow the furcation of the roots.

The cross-section areas of the mesio-buccal and mesio-lingual canals as well as the SDF were precisely measured through a computer-assisted evaluation. Calibration of each image captured by the computer decreased the possibility of distortion.

After statistical treatment of the results, statistically significant differences were observed between the cross-section area after instrumentation and the GG sequences, as well as in relation to the SDF.

The greatest cross-section area increase was observed in sample 27 from G2 (mesio-lingual canal - serial sequence), in which the canal area was 7.4 times bigger, and in sample 7 from G1 (mesio-buccal canal - crown-down sequence), in which the canal area was 2.1 times bigger.

Although it was not possible to observe anatomic relationship between samples, it was clear that the use of GG drills in the serial sequence tended to result in a stronger increase of the cross-section area.

The increase of the cross-section area tended to be directly associated to the decrease of the distance between the canal and the furcation. The tendency of greater wear after the use of a serial sequence could be seen in two samples, in which a total rupture of the dentine/cementum wall leading to the furcation area could be observed.

Remaining dentine thickness following various intra-radicular procedures may be the most important iatrogenic factor correlating to future root resistance against fracture $^{16}$. Lim, Stock ${ }^{8}$ (1987) established in their study a limit of 0.2 and $0.3 \mathrm{~mm}$ of dentine thickness as a measurement in which the resultant forces of condensation during obturation would not result in tooth fracture. Having this in mind, samples in G1 (mesio-buccal canal - crown-down sequence) presented wall thickness greater then the limits established. On the other hand, 9 samples $(37.5 \%)$ in G2 (mesio-lingual canal - serial sequence) presented inferior wall thickness, leaving them out of the safety limit. Through the results of the present study it was possible to conclude that GG drills, used in a crown-down sequence, offer the operator a greater safety margin.

Other authors ${ }^{7,17,18}$ corroborate this statement, believing that the crown-down sequence is safer, since the larger burs tend to penetrate less deeply into the canal, avoiding a great and unnecessary wear of the dentine walls.

Throughout this experiment it was observed that samples always suffer greater wear nearest to the "Risk Zone" rather than the "Safety Zone", which was also seen in the studies of Abou-Rass et al. ${ }^{5}$ (1980) and Cunningham, Senia ${ }^{6}$ (1992). According to Abou-Rass, Jastrab ${ }^{19}$ (1982), the GG drills are safe to use and the occurrence of instrument separation (of which the removal is usually simple) is often a result of inadequate manipulation. Although this was not the objective of this work, no instrument separation was observed during the instrumentation of the 36 samples.

\section{Conclusion}

When considered within the limitations of this study, the results indicate that the remaining dentine/cementum thickness after molar cervical preparations using Gates-Glidden burs was greater in the crown-down sequence than in the serial sequence. 


\section{References}

1. Grossman L. A brief history of endodontics. J Endod. 1982;8(1):538.

2. Mullaney TP. Instrumentation of finely curved canals. Dent Clin North Am. 1979;23(4):575-92.

3. Taintor JF. Use of the gates glidden bur in endodontics. J Nebr Dent Assoc. 1978;54(3):10-2.

4. Weine FS, Kelly RF, Lio PJ. The effect of preparation procedures on original canal shape and on apical foramen shape. J Endod. 1975;1(8):255-62.

5. Abou-Rass M, Frank AL, Glick DH. The anticurvature filing method to prepare the curved root canal. J Am Dent Assoc. 1980;101(5):792-4.

6. Cunningham CJ, Senia SE. A three-dimensional study of canal curvatures in the mesial roots of mandibular molars. J Endod. 1992;18(6):294-300.

7. Coutinho-Filho T, De-Deus G, Guimarães T, Gurgel-Filho ED, Maniglia-Ferreira C. A computer evaluation of the dentin remaining after cervical preparation in curved canals: Gatesglidden drills vs. orifice shaper. Braz J Oral Sci. 2002;1(3):11620.

8. Lim SS, Stock CJ. The risk of perforation in the curved canal: anticurvature filing compared with the step-back technique. Int Endod J. 1987;20(1):33-9.

9. Isom TL, Marshall JG, Baumgartner JC. Evaluation of root thickness in curved canals after flaring. J Endod. 1995;21(7):368-71.

10. Gluskin AH, Brown DC, Buchanan LS. A reconstructed computerized tomographic comparison of Ni-Ti rotary GT files versus traditional instruments in canals shaped by novice operators. Int Endod J. 2001;34(6):476-84.

11. Schilder H. Cleaning and shaping the root canal. Dent Clin North Am. 1974;18(2):269-96.

12. Bramante CM, Berbet A, Borges RP. A methodology for evaluation of root canal instrumentation. J Endod. 1987;13(5):2435.

13. Bower RC. Furcation morphology relative to periodontal treatment. Furcation entrance architecture. J Periodontol. 1979;50(1):23-7.

14. Kessler JR, Peters DD, Lorton L. Comparison of the relative risk of molar root perforations using various endodontic instrumentation techniques. J Endod. 1983;9(10):439-47.

15. McCann JT, Keller DL, LaBounty GL. A modification of the muffle model system to study root canal morphology. J Endod. 1990;16(3):114-5.

16. Pilo R, Corcino G, Tamse A. Residual dentin thickness in mandibular premolars prepared with hand and rotatory instruments. J Endod. 1998;24(6):401-4.

17. Torabinejad M, Rotstein L, Stabholz A. Effect of preflaring on tactile detection of the apical constriction. J Endod. 1995;21(2):92-4.

18. West JD, Roane JB. Limpeza e modelagem do sistema de canais radiculares. In: Cohen S, Burns RC. Caminhos da polpa. $7^{\text {th }}$ ed. Rio de Janeiro: Guanabara Koogan; 2000. p. 206-36.

19. Abou-Rass M, Jastrab RJ. The use of rotary instruments as auxiliary aids to root canal preparation of molars. J Endod. 1982;8(2):78-8. 